\title{
Disease Pattern and Outcome among Neonates in Pediatric Ward of POF Hospital, Wah
}

\author{
Robina Mushtaq ${ }^{1}$, Musarat Ramzan ${ }^{2,3}$, Anum Jehan ${ }^{4}$, Aqsa Mushtaq ${ }^{4}$, Areeba Siddiqui $^{4}$, Abdul Basit $^{4}$, \\ Aroosha Arif ${ }^{4}$, Ali Farooq ${ }^{4}$ \\ ${ }^{1}$ Associate Professor, Department of Community Medicine, Wah Medical College \\ ${ }^{2}$ Dean, Wah Medical College \\ ${ }^{3}$ Professor and Head, Department of Community Medicine, Wah Medical College \\ ${ }^{4}$ House officer, POF Hospital, Wah Medical College
}

\begin{abstract}
AB S TRACT
Background: Neonatal period is the duration between 0-28 days of birth and it is the most vulnerable period of life because of the exposure of the neonate to a large number of problems and diseases during this period. The objective of the study was to determine the disease pattern and outcome among neonates in Pediatric ward of POF Hospital.

Material and Methods: A descriptive study was carried out at Pediatric ward of POF Hospital Wah Cantt. Retrospective data regarding age, sex, reasons for admission, outcome and mode of delivery (from hospital record) was collected for all neonates admitted during the year 2016 from $1^{\text {st }}$ January to $31^{\text {st }}$ December. The data was analyzed by using SPSS version-19.

Results: Among total neonates $(n=887)$ admitted during the year, $63.2 \%$ were males and $36.8 \%$ were females. Mean weight of neonates was $2.54 \pm 0.75 \mathrm{~kg}$ while mean age was $2.39 \pm 5.8$ days. Most common causes of hospital admissions were Prematurity, Respiratory Distress Syndrome, Seizures and Sepsis. Overall, $82.64 \%$ recovered from their illness while $17.02 \%$ expired.

Conclusion(s): Prematurity, respiratory distress syndrome, seizures and sepsis were the major causes of neonatal admission in this study.

Key words: Diagnostic value, Immature-to-total neutrophil ratio, Neonatal sepsis

Authors' Contribution: Correspondence:

${ }^{1}$ Conception; 2-3Literature research; Robina Mushtaq

manuscript design and drafting; ${ }^{4}$ Critical

analysis and manuscript review; Data analysis; 7,8Manuscript Editing.

Cite this article. Mushtaq $R$, Ramzan $M$, Jehan $A$, Mushtaq A, Siddiqui A, Basit A, Arif $A$, Farooq A. Disease Pattern and Outcome among Neonates in Pediatric Ward of POF Hospital, Wah. J Islamabad Med Dental Coll.2020; 9(1):42-47. Doi: 10.35787/jimdc.v9i1.386

Article info:

Received: July 22, 2019

Accepted: February 20, 2020
\end{abstract}

\section{Introduction}

Neonatal period is defined as the first 28 days of life and is further divided into very early (birth to 24 hours), early ( 24 hours to 7 days) and late neonatal period ( 7 days to 28 days). ${ }^{1}$

Worldwide, 130 million neonates are born each year, of these, 4 million die in first 28 days of life. Neonatal period ( $1^{\text {st }} 28$ days of life) is the most fragile and vulnerable period of life, because of the large number of problems and diseases which a neonate is likely to face. Moreover, a neonate is 500 times more likely to die on the first day of life than at one month of age ${ }^{1-5}$

Two third of the world's total neonatal deaths occur in just 10 countries, mostly in Asia. Pakistan 
ranks at number three among these countries. With a reported neonatal mortality rate of 49 per 1000 live births, Pakistan alone accounts for $7 \%$ of global neonatal deaths. In the developed countries, the main cause of mortality and morbidity in the neonatal period are non-preventable like congenital anomalies, but in the developing countries preventable causes such as infections, jaundice, birth asphyxia and pneumonia predominate. $^{5}$

The neonatal disease pattern is different from place to place and changes over time. It is believed that majority of the causes of neonatal morbidity are preventable. Throughout the world, the major reasons of neonatal mortality were estimated to be infections (35\%), pre-term births (28\%) and asphyxia (23\%). ${ }^{2}$ Sepsis is the main cause of deaths in newborn babies. Approximately, $20 \%$ of all newborn babies develop sepsis and each year in developing countries, sepsis is liable for $30-50 \%$ of the total neonatal deaths. ${ }^{2,6}$

Pre maturity alone accounts for majority of highrisk newborns as they are likely to face a large number of problems.

Though considerable improvement has occurred in the survival of newborns in advanced countries, but the mortality rate is still very high in the developing countries. Neonatal mortality and disease pattern are a sensitive indicator of availability, utilization and effectiveness of mother and child health services in the community. ${ }^{1,5}$

The survival of the newborns depends upon the care, they receive. In most tertiary care institutions, a special unit is reserved for babies with illnesses in the neonatal period. Prognosis of sick neonates depends upon severity of intrinsic illness and provided medical care. Majority of the causes of neonatal morbidity and mortality in our country are preventable. Lack of obstetrical and neonatal services, poor infrastructure of primary health care, and low awareness of the health needs of pregnant women are the contributory factors. ${ }^{3,4}$

The objective of the study was to determine the disease pattern and outcome among neonates in Pediatric ward of POF Hospital. In developed countries like Pakistan, the neonatal morbidity and mortality is high. One of the important factors responsible for this is insufficient neonatal care at most of the hospitals. This study was conducted to find out the major diseases among neonates in Wah Cantt region, so that measures can be taken to initiate a program for better management of neonatal problems in order to reduce morbidity and mortality.

\section{Material and Methods}

A descriptive study was carried out at Pediatric ward of POF Hospital Wah Cantt. Retrospective data regarding age, sex, reasons for admission, outcome and mode of delivery was collected from hospital record for all neonates admitted during the year 2016 from $1^{\text {st }}$ January to $31^{\text {st }}$ December. The data was analyzed by using SPSS version 19 . Chisquare test of significance was used to determine association between categorical variables at alpha value of 0.05 .

Diagnosis was largely on clinical findings with specific Laboratory and/or X-Ray findings. Sepsis was diagnosed clinically along with complete blood count ( $\mathrm{CBC}$ ), and positive blood culture. Congenital heart disease was confirmed by Echocardiography. Neonates delivered before 37 weeks of gestation were labeled pre-mature and those having birth weight less than $2.5 \mathrm{Kg}$ were classified as low birth weight.

Neonates were diagnosed with intrauterine growth retardation (IUGR) when their weight was below the $10^{\text {th }}$ percentile for the gestational age. Neonatal jaundice was diagnosed by checking serum Bilirubin. Pneumonia was diagnosed by 
clinical examination (respiratory rate $\geq 60$ per minute and indrawing of chest wall) and radiological findings.

\section{Results}

In this study, a total of 887 neonates were admitted in Pediatric ward of POF Hospital, Wah Cantt, from January 1 to December 31, 2016. Among them, $63.2 \%$ were males and $36.8 \%$ were females. Most of the neonates admitted were delivered through C-Section (56\%). The mean age of neonates was $2.39 \pm 5.8$ days with $67 \%$ born within 24 hours, $22 \%$ aged 1-7 days, while $11 \%$ were more than 7 days old (Table I). The mean weight of neonates was $2.54 \pm 0.75 \mathrm{~kg}$. Overall, $82.64 \%(n=733)$ recovered while $17.02 \%(n=154)$ expired and only $0.33 \%(n=3)$ were referred to other hospitals. About 330 (37.2\%) patients were referred from OPD of POF hospital, 277 (31.2\%) from Operation Theatre (OT), 138 (15.6\%) from Gynecology ward and 4 (0.5\%) were reported from Emergency of same hospital, while 138 (15.6\%) were referred from other hospitals.

The main causes of hospital admissions included sepsis (243; 27.4\%), Respiratory Distress Syndrome (180; 20.3\%), Seizures (107; 12.1\%) and preterm neonates $(107 ; 12.1 \%)$. There were $71(8 \%)$ cases of neonatal jaundice, 59 (6.7\%) cases of Meconium Aspiration Syndrome, 42 (4.7\%) of Pneumonia, 29 (3.3\%) of Intra Uterine Growth Restriction, 13 (1.5\%) of Congenital Heart Disease, and 36(4\%) had miscellaneous diseases (Table I).

The most common cause in both males and females was prematurity (preterm neonates) $167 ; 11.94 \%$ in males and 40; $7.1 \%$ in females), Respiratory Distress Syndrome (111; 19.78\% in males and 63; $19.32 \%$ in females), Seizures $(67 ; 11.94 \%$ in males and $40 ; 12.26 \%)$ and Sepsis (155; 27.62\% in males and $88 ; 26.99 \%$ in females) (Figure 1). Regarding weight and gender 224 (25.2\%) males and 161 (18.7\%) females were underweight. Mode of delivery had no significant effect on mortality (16.7\% in C-section vs $17.4 \%$ in SVD) (Table I).

Disease pattern according to mode of delivery is shown in Table II. Regarding outcome, higher mortality rates were noted among neonates having Respiratory Distress Syndrome (49; 27.2\%), Prematurity (40;37.3\%) and Sepsis (26; 10.7\%), and in neonates who were admitted within 24 hours after delivery (Table I). Disease pattern according to age is shown in Figure 2

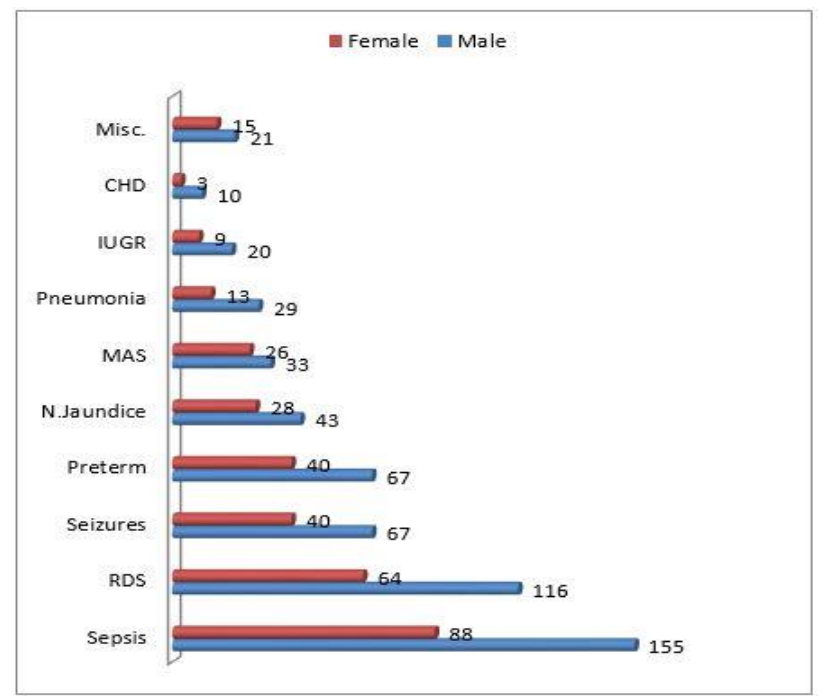

Figure 1: Frequency distribution of diseases according to gender

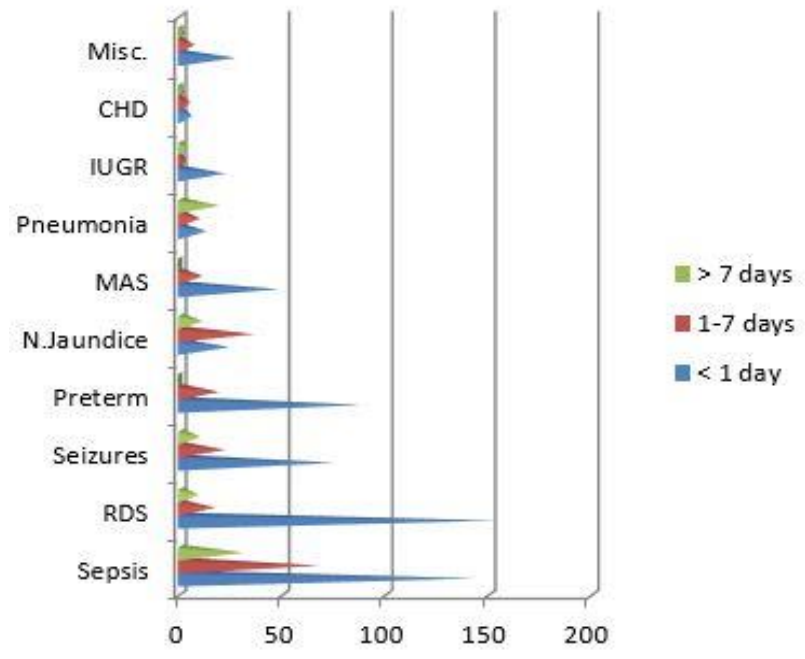

Figure 2: Disease pattern according to age groups 


\begin{tabular}{|c|c|c|c|c|c|c|}
\hline \multirow{2}{*}{ Variables } & \multirow{2}{*}{ Attributes } & \multirow{2}{*}{ Frequency } & \multicolumn{3}{|c|}{ Outcome } & \multirow{2}{*}{$P$-value } \\
\hline & & & Recovered & Expired & Referred & \\
\hline \multirow{2}{*}{ Gender } & Male & 561 & 462 & 98 & 1 & \multirow{2}{*}{0.52} \\
\hline & Female & 326 & 271 & 53 & 2 & \\
\hline \multirow{2}{*}{$\begin{array}{l}\text { Mode of } \\
\text { delivery }\end{array}$} & C-section & 497 & 411 & 83 & 3 & \multirow{2}{*}{0.170} \\
\hline & SVD & 390 & 322 & 68 & 0 & \\
\hline \multirow{3}{*}{$\begin{array}{l}\text { Age at } \\
\text { admission }\end{array}$} & $<1$ day & 598 & 474 & 121 & 3 & \multirow{3}{*}{0.000} \\
\hline & 1-7 days & 195 & 170 & 25 & 0 & \\
\hline & $>7$ days & 94 & 89 & 5 & 0 & \\
\hline \multirow{10}{*}{ Diagnosis } & Sepsis & 243 & 216 & 26 & 1 & \multirow{10}{*}{0.000} \\
\hline & Respiratory Distress Syndrome & 180 & 129 & 49 & 2 & \\
\hline & Seizures & 107 & 104 & 3 & 0 & \\
\hline & Preterm & 107 & 67 & 40 & 0 & \\
\hline & Neonatal Jaundice & 71 & 69 & 2 & 0 & \\
\hline & Meconium Aspiration Syndrome & 59 & 50 & 9 & 0 & \\
\hline & Pneumonia & 42 & 37 & 5 & 0 & \\
\hline & IUGR & 29 & 22 & 7 & 0 & \\
\hline & Congenital Heart Disease & 13 & 6 & 7 & 0 & \\
\hline & Miscellaneous & 36 & 33 & 3 & 0 & \\
\hline
\end{tabular}

Table II: Disease pattern according to mode of delivery

\begin{tabular}{|l|c|c|c|}
\hline \multirow{2}{*}{ Disease at admission } & \multicolumn{2}{|c|}{ Delivery Mode } & \multirow{2}{*}{ Total } \\
\cline { 2 - 3 } & $\begin{array}{c}\text { C- } \\
\text { section }\end{array}$ & SVD & \\
\hline Sepsis & 125 & 118 & 243 \\
\hline Respiratory Distress Syndrome & 112 & 68 & 180 \\
\hline Seizures & 75 & 32 & 107 \\
\hline Preterm & 59 & 48 & 107 \\
\hline Neonatal Jaundice & 32 & 39 & 71 \\
\hline Meconium Aspiration Syndrome & 31 & 28 & 59 \\
\hline Pneumonia & 21 & 21 & 42 \\
\hline IUGR & 16 & 13 & 29 \\
\hline Congenital Heart Disease & 7 & 6 & 13 \\
\hline Miscellaneous & 19 & 17 & 36 \\
\hline
\end{tabular}

Discussion

This study was conducted in Pediatric ward of POF Hospital, Wah Cantt to study the disease pattern and outcome among neonates. The percentage of male patient was $63.2 \%$ while that of female was $36.8 \%$. This high proportion of male neonates is due to their genetic liability to many diseases as has been shown in a number of studies. ${ }^{7-10}$ Moreover studies conducted in tertiary care neonatal unit, Kharian, Nishtar Hospital Multan, teaching hospital of Oghera, Nigeria and in Rehman Medical Institute, Peshawar also showed male predominance in neonate's admitted in pediatric ward. ${ }^{1-3,5}$
The percentage of neonates delivered through CSection was $56 \%$ with similar results reported in tertiary care hospital, Kharian, while in contrast Sheikh Zayed Hospital, Lahore reported $36 \%$ of neonates born by C-Section..$^{2,7}$ Mortality among neonates delivered by $\mathrm{C}$-section was insignificantly lower as compared to SVD (16.7\% vs $17.4 \%)$. The reasons may be poor practices in labour rooms with aseptic techniques (clean hands, clean delivery surface and better cord care) not being properly practiced in our community. More cesarean sections are noted in our society because many patients do not avail antenatal services and report in serious situation after being handled by local dais, making CS necessary to save the life of mother as well as fetus. $^{7}$

At the time of admission, $67 \%$ babies were less than 24 hours of age, as this period is vital for neonatal morbidity and mortality. In studies conducted by Saleem et al, Ali et al, and Rahim et al, majority of the neonates were born within 24 hours. ${ }^{7,8,10}$ However, Parkash and Das reported only $18 \%$ neonates admitted during 24 hours. ${ }^{11}$ In our study $44 \%$ neonates were underweight, while $56 \%$ were in normal birth weight range. Many of the other studies in Multan, northern Nigeria, and delta 
region of Nigeria also had more number of neonates in normal birth weight range, ${ }^{6,5,12}$ while the studies held in Peshawar and Kharian showed more cases in low birth weight range..$^{1,2}$ The main causes for low birth weight in our region are low literacy rate, lack of proper antenatal services, poverty and high rate of malnutrition among mothers.

Most common clinical conditions of neonates in our study are sepsis, RDS, prematurity and seizures making $71.2 \%$ of all diseases. These results are similar to many local studies,,$^{2,3,13,14}$ as well as researches in other countries ${ }^{5,15-18}$ with almost the same disease pattern. In contrast, a research carried out in Peshawar had maximum admissions due to low birth weight and IUGR. ${ }^{1}$ In a study by Udo et al and Quddusi et al infections and birth asphyxia are the main reasons for admission of neonates, respectively. ${ }^{6,19}$

In our study, majority of patients (83\%) recovered thus showing more recovery index and low mortality. This reflects quality of care being provided at hospital as well as dedication and hard work of health care providers. Worldwide the trend of neonatal mortality is on the decline. ${ }^{7}$ Similar death trends among neonates was observed in different studies conducted in Pakistan ${ }^{2}, 10$ and Nigeria. ${ }^{5,12}$ As compared to our study, researches carried out in Peshawar, Multan and Karachi showed lower mortality rate ${ }^{1,6,8}$ while studies by Saleem et al, Rakhia et al and Parkash and Das have revealed somewhat higher mortality rates. ${ }^{4,11,14}$ Higher death rates were noted among neonates having Respiratory Distress Syndrome (32.4\%), prematurity (26.4\%) and sepsis (17.2\%). These diseases were also responsible for mortality in neonates in a study by Saini et al. ${ }^{20}$ Sepsis was the leading cause in study by Aijaz et $\mathrm{al}^{13}$ while prematurity and respiratory problems were main causes of death in study by Tekleab et al. ${ }^{17}$ As neonates are more susceptible to death within first
7 days of their life, in our study $96 \%$ deaths were recorded during this period, of which $80 \%$ neonates died within 24 hours after delivery. These results are comparable with other regional and international studies, respectively. ${ }^{7,16,19}$

\section{Conclusion}

Prematurity, Respiratory Distress Syndrome, seizures and sepsis were the major causes of neonatal admissions in our study population. Proper antenatal and natal care of pregnant women, timely intervention and referral of all high risk pregnancies can significantly reduce neonatal admission due to these causes.

\section{References}

1. Jan AZ, Ahmad S, Zahid SB. Clinical audit of admission pattern and its outcome in a neonatal ICU. Gomal J Med Sci. 2013; 11(1): 31-6.

2. Hussain S. Neonatal morbidity and mortality pattern in a tertiary care neonatal unit of a teaching hospital. Ann Pak. Inst. Med. Sci. 2014; 10(1): 7-11.

3. Tabassum S, Ameen M, Akram M, Amanullah $M$. Prevalence of neonatal diseases in Multan Region, Pakistan. Pakistan Journal of Nutrition. 2013; 12(6): 544-548. Doi: 10.3923/pjn.2013.544.548

4. Saleem M, Ali M, Anwar J, Babar MI, Rafi M, Mehmood R, et al. Clinical audit of neonatal admissions in a tertiary care hospital. JSZMC. 2010; 2(4). 231-235.

5. Ugwu GIM. Pattern of morbidity and mortality in newborn special care unit in a tertiary institution in the Niger Delta region of Nigeria: A two years prospective study. Glo. Adv. Res. J. Med. Med. Sci. 2012; 1(6): $133-138$.

6. Quddosi Al, Razzaq A, Hussain S, Hussain A. Pattern of neonatal admission at children's hospital and the institute of child health, Multan. J. Ayub Med. Coll Abbotabad. 2012; 24(2). 108-110.

7. Saleem M, Iqbal R, Bokhari S, Ali M, Khan Z. Pattern of Neonatal Admissions \& its outcome in a tertiary care hospital of Southern Punjab (5 years study). P J M H S. 2014; 8(4): 916-921.

8. Ali SR, Ahmed S, Lohana H. Disease Patterns and Outcomes of Neonatal Admissions at a Secondary Care Hospital in Pakistan. Sultan Qaboos Univ Med J. 2013; 13(3): 424-428. PMID: 23984028

9. Tabassum S, Amin M, Akram M, Aman Ullah M. Prevalence of Neonatal Diseases in Multan Region, 
Pakistan. Pak J Nutr. 2013; 12(6): 544-548. Doi: 10.3923/pjn.2013.544.548

10. Rahim F, Jan A, Mohummad J, Iqbal H. Pattern and outcome of admissions to neonatal unit of Khyber Teaching Hospital, Peshawar. Pak J Med Sci. 2007; 23(2): 249- 253.

11. Parkash J, Das N. Pattern of admissions to neonatal unit. JCPSP. 2005; 15(6): 341-344. Doi: $06.2005 / j c p s p .341344$

12. Mukhtar-Yola $M$, Iliyasu Z. A review of neonatal morbidity and mortality in Aminu Kano Teaching Hospital, northern Nigeria. Trop Doc. 2007; 37(3): 130-132. Doi: 10.1258/004947507781524683

13. Aijaz N, Huda N, Kausar S. Disease Burden of NICU, at a Tertiary Care Hospital, Karachi. J Dow Univ Health Sci. 2012; 6(1): 32-35.

14. Rakhia A, Khan M, Memon AA, Dahar SA. Pattern and Outcome of Neonatal Ailments in a Tertiary Care Hospital. Pak J Med Res. 2014; 53(1): 14-16.

15. Okposio MM, Ighosewe OI. Morbidity and mortality pattern among neonates admitted to the general paediatric ward of a secondary health care centre in the Niger delta region of Nigeria. Sri Lanka J. Child Health. 2016; 45(2): 84-89. Doi: 10.4038/sljch.v45i2.7981
16. Okechukwu AA, Achonwa A. Morbidity and mortality patterns of admissions into the Special care baby unit of University of Abuja Teaching Hospital, Gwagwalada, Nigeria. Niger J Clin Pract. 2009; 12(4): 389-394. PMID: 20329678

17. Tekleab AM, Amaru GM, Tefera YA. Reasons for admission and neonatal outcome in the neonatal care unit of a tertiary care hospital in Addis Ababa: a prospective study. Research and Reports in Neonatology. 2016; 6: 17-23. Doi: 10.2147/RRN.S95455

18. Kunle-Olowu OE, Peterside O, Adeyemi OO. Prevalence and Outcome of Preterm Admissions at the Neonatal Unit of a Tertiary Health Centre in Southern Nigeria. OJPED. 2014; 4(1): 67-75. Doi: 10.4236/ojped.2014.41009

19. Udo JJ, Anah MU, Ochigbo SO, Etuck IS, Ekanem AD. Neonatal Morbidity and Mortality In Calabar, Nigeria: A Hospital- Based Study. Niger J Clin Pract. 2008; 11(3): 285-289. PMID: 19140371

20. Saini N, Chhabra S, Chhabra S, Garg L, Garg N. Pattern of neonatal morbidity and mortality: A prospective study in a District Hospital in Urban India. J Clin Neonatol. 2016; 5:183-8. Doi: 10.4103/2249-4847.191258 